Vol. 2, n. 3 - Edição Especial: Ciclos Formativos em Ensino de Ciências.

\title{
Diário de Bordo em aulas de Epistemologia: contribuições na formação inicial de professores de Química
}

\section{Logbook in Epistemology classes: contributions in the initial formation of chemistry teachers}

\author{
Fabiane de Andrade Leite (fabiane.leite @uffs.edu.br) \\ Universidade Federal da Fronteira Sul - UFFS
}

\begin{abstract}
Resumo: Apresento neste texto um relato de experiência com o objetivo de compartilhar as compreensões de licenciandos, de $1^{\text {a }}$ fase do Curso de Química da Universidade Federal da Fronteira Sul Campus Cerro Largo, acerca da docência. O objeto de investigação foram as escritas realizadas pelos licenciandos em diários de bordo ao longo de 18 encontros realizados no componente curricular de Epistemologia e o Ensino de Ciências no segundo semestre de 2018. Por meio de uma análise qualitativa das escritas identificou-se três categorias formativas, sendo elas: não reflexiva, reflexiva excludente e reflexiva inclusiva. Acena-se o potencial do uso do diário de bordo para a construção da identidade docente em Química e o reconhecimento da área de ensino de Ciências da Natureza como principais aspectos formativos desenvolvidos por meio das discussões e leituras realizadas acerca da natureza do conhecimento científico.
\end{abstract}

Palavras-chave: Escrita reflexiva; Epistemologia; Docência em Química.

\begin{abstract}
Present in this text an experience report with the objective of sharing the understandings of undergraduates, of the 1st phase of the Chemistry Course of the Federal University of Fronteira Sul Campus Cerro Largo, about teaching. The object of investigation was the writings made by the undergraduates in logbooks during 18 meetings held in the curricular component of Epistemology and Science Teaching in the second semester of 2018. Through a qualitative analysis of the writings, three formative categories were identified, namely: non-reflexive, exclusionary reflexive and inclusive reflexive. The potential of the use of the logbook for the construction of the teaching identity in Chemistry and the recognition of the area of Natural Sciences teaching as main formative aspects developed through the discussions and readings about the nature of scientific knowledge is emphasized.
\end{abstract}

Keywords: reflective writing; epistemology; chemistry teaching. 


\section{Vol. 2, n. 3 - Edição Especial: Ciclos Formativos em Ensino de Ciências.}

\section{INTRODUÇÃO}

A formação de professores é tema de fundamental importância dentre as políticas públicas para a educação, pois interfere na melhoria da Educação Básica brasileira. Com isso, a formação inicial de professores tem sido temática recorrente nas discussões educacionais, em especial a partir da década de 90 do século passado, período em que os cursos de licenciatura tiveram maior atenção tendo em vista o olhar diferenciado dado pela lei 9394/96, Lei de Diretrizes e Bases da Educação Nacional (LDB), ao processo de formação inicial e continuada de professores para a educação básica. De acordo com o artigo 62 da LDB, a formação docente "far-se-á em nível superior, em curso de licenciatura plena, admitida, como formação mínima para o exercício do magistério" (BRASIL, 1996).

Ainda, no que se refere a formação de professores, tivemos no ano de 2015 um importante movimento de reformulação dos currículos dos cursos de licenciatura, decorrente da resolução 2/2015 do Conselho Nacional de Educação que define as diretrizes curriculares nacionais para a formação inicial de em nível superior e para a formação continuada. A reformulação decorre da alteração da carga hora destinada à organização do trabalho acadêmico, ainda, destaco a inserção da formação embasada na compreensão epistemológica do conhecimento.

Nesse sentido, o curso de Química da Universidade Federal da Fronteira Sul (UFFS), Campus Cerro Largo, realizou ao longo do ano de 2017, as adequações no Projeto Pedagógico do Curso (PPC), que se efetivaram com o ingresso da primeira turma no novo PPC no ano de 2018. Sendo uma das alterações a inserção do Componente Curricular (CCR) de Prática de Ensino: Epistemologia e Ensino de Ciências na $1^{\text {a }}$ fase do curso, contemplando uma carga horária de 60 horas/aula. Cabe destacar que no PPC antigo (2013) havia um CCR similar, denominado Epistemologia e História da Ciência oferecido em fase mais adiantada do curso e com menor carga horária.

O CCR de Epistemologia tem como objetivo principal discutir concepções de Ciência e docência articulados a processos de ensino, aos modelos de produção da Ciência 


\title{
Vol. 2, n. 3 - Edição Especial: Ciclos Formativos em Ensino de Ciências.
}

e sua historicidade para contextualizar os paradigmas que orientam a produção do conhecimento na área das Ciências do Ensino de Ciências, favorecendo o desenvolvimento do pensamento crítico (UFFS, 2017).

Com as alterações realizadas no projeto do curso a primeira turma no novo PPC teve início ano de 2018. A turma teve, no primeiro semestre do curso, a realização da primeira prática de ensino, a de Epistemologia. Nesse sentido, o presente relato decorre do interesse em compartilhar as contribuições das discussões epistemológicas realizadas nesta etapa formativa, buscando identificar de que forma tais aspectos contribuem para a formação de professores.

$\mathrm{O}$ objeto de estudo do presente relato foram as escritas reflexivas realizadas pelos futuros professores acerca das aulas de Epistemologia. Cabe destacar que o processo de reflexão tem sido um alicerce formativo nas aulas de práticas de ensino que realizo e, com isso, compreendo que, mesmo em fase inicial de curso, os licenciandos precisam ter contato com estratégias que exijam reflexão permanente da prática realizada. Para tanto, tenho proporcionado aos licenciandos a realização de um diário de bordo em que eles possam escrever aspectos que marcam a vivência.

No diário prioriza-se a reflexão da prática, conforme proposto por Zeichner (1993, $\mathrm{p}, 16)$,

\begin{abstract}
reflexão também significa o reconhecimento de que a produção de conhecimento sobre o que é um ensino de qualidade não é propriedade exclusiva das universidades e centros de investigação e desenvolvimento e de que os professores também têm teorias que podem contribuir para uma base codificada de conhecimentos de ensino.
\end{abstract}

Assim, busco relatar, na sequência, aspectos significativos do processo realizado na prática de ensino e as discussões das contribuições do diário na formação inicial de professores de Química.

\section{METODOLOGIA}




\section{Vol. 2, n. 3 - Edição Especial: Ciclos Formativos em Ensino de Ciências.}

O contexto do presente relato é o CCR de Epistemologia e o Ensino de Ciências, que foi ofertado para a $1^{a}$ fase do curso de Química Licenciatura da UFFS no primeiro semestre de 2018. As atividades foram realizadas ao longo de dezoito encontros semanais em que os vinte e quatro licenciandos matriculados participaram ativamente, por meio de leituras e discussões de referenciais e, em especial, por meio de escritas nos diários de bordo (DB), objeto de investigação do presente relato.

O diário de bordo constitui-se como instrumento formativo (PORLÁN; MARTIN, 2000), e foi apresentado aos licenciandos no primeiro encontro. De acordo com os autores, "Su utilización periódica permite reflejar el punto de vista del autor sobre los processos más significativos de la dinâmica em la que está imerso" (PORLÁN; MARTIN, p. 19, 2000).

No decorrer dos cinco primeiros encontros foram realizadas leituras das reflexões escritas nos DB conforme o interesse dos licenciandos, nesse momento ocorreram intervenções orais da professora da turma que, por meio de questionamentos, buscava fomentar escritas cada vez mais reflexivas. Saliento que a escrita no DB não era obrigatória, mas muito comentada em aula a fim de despertar o interesse de cada um na realização da atividade formativa.

O DB foi recolhido em dois momentos, o primeiro momento ocorreu após os nove primeiros encontros, quando a leitura teve como objetivo verificar contribuições ao processo formativo das discussões realizadas e, com isso, delinear novos rumos para as aulas. E, o segundo momento ocorreu na penúltima aula do semestre a fim de identificar mudanças nas perspectivas epistemológicas dos licenciandos. Cabe destacar, que o componente de Epistemologia é o articulador do eixo temático na primeira fase do Curso. De acordo com o PPC do Curso:

[...] a interação das áreas que constituem o currículo é promovida na otimização de eixos temáticos anuais que perpassam os processos teóricos e práticos, sendo desenvolvidos por atividades definidas no Colegiado do Curso e assumidas por todos os professores que atuam no semestre letivo. (UFFS, 2018, p. 33) 


\section{Vol. 2, n. 3 - Edição Especial: Ciclos Formativos em Ensino de Ciências.}

Assim, no DB os licenciandos eram motivados a relatar aspectos marcantes para a sua formação docente que ocorriam nos demais CCRs.

\section{DISCUSSÃO DA PRÁTICA}

A leitura no DB dos licenciandos tem sido uma prática recorrente nas aulas que realizo no curso de Química, pois tenho identificado possibilidades de desenvolvimento profissional no processo de escrita reflexiva dos alunos. E dessa vez não foi diferente, porém considerando que tive acesso aos DBs em dois momentos consegui rever minha prática no componente curricular o que contribuiu muito para analisar as principais contribuições do CCR para a formação docente.

Assim, nas nove primeiras semanas de aula organizei as atividades de maneira que as discussões gerassem mais dúvidas do que certezas entre os alunos, o foco das aulas eram questionamentos que pudessem despertar o interesse em permanecer no Curso e compartilhar experiências que possibilitaram aos licenciandos compreender a importância da profissão escolhida.

Após os nove primeiros encontros realizei a leitura de dezessete diários apenas, pois os demais não quiseram compartilhar suas reflexões. Por meio de uma análise de conteúdo (BARDIN, 2011), busquei organizar as escritas iniciais, porém todas se caracterizam como descritivas, ou não reflexivas. Isso corrobora a afirmação de Porlán e Martin (2000, p. 21), “Al comenzar el diario se suelen tener una visión simplificada y poco diferenciada de la realidad". Neste momento, destaco a importância da minha intervenção para não desmotivá-los no processo de escrita e manter o interesse em aprofundar a reflexão nas aulas. As descrições se caracterizaram como relato fiel do que ocorreu na aula, como se não houvessem alunos, nem falas, apenas com o que estava sendo passado no quadro, ou seja, os licenciandos transcreveram nos DBs o que colocaram nos seus cadernos de aula, os registros das informações que estavam sendo abordadas na aula, sem comentários ou discussões. 


\section{Vol. 2, n. 3 - Edição Especial: Ciclos Formativos em Ensino de Ciências.}

Após esse primeiro momento entreguei aos licenciandos os DBs com escritas motivadoras e contendo vários questionamentos acerca do que havíamos discutido em aula. No dia da entrega surgiram vários comentários em aula sobre as escritas, o que contribuiu para compreenderem a importância de refletirem sobre as discussões em aula na forma de escrita. Assim, nas demais aulas, o assunto do DB vinha sempre à tona, por meio de questões buscava suscitar nos licenciandos interesse em relatar algo.

No segundo momento de leitura dos DBs, fui surpreendida com as escritas, alguns mudaram de forma muito significativa. As mudanças permitiram com que eu organizasse as reflexões em três categorias formativas, sendo a primeira não reflexiva, outra reflexiva excludente e uma terceira categoria denominada reflexiva inclusiva.

$\mathrm{Na}$ categoria não reflexiva foram alocados três escritas em DBs de licenciandos, que descreveram de forma objetiva as atividades realizadas em aula, na forma de itens. Considero esse tipo de escrita o início do processo, ainda há necessidade de intervenção para que posteriormente o próprio licenciando consiga rever suas perspectivas e identifique situações que marcam sua formação. É uma escrita que está em processo de evolução, porém, nesse momento, não apresentam contribuições ao processo formativo.

Como escrita não reflexiva destaco o recorte realizado no diário de L1, que descreve com fidelidade todos os momentos da uma aula:

"No dia 04 de maio, na aula de epistemologia, a professora falou sobre a importância da epistemologia na formação de professores. Apresentou slides e pediu que os colegas respondessem uma pergunta, todos responderam e tiveram que falar a respeito". (DB, L1, 2018)

No excerto o licenciando não aparece como personagem da história, não se inclui no processo. Tal característica é normal nas escritas iniciais, porém considerando a participação de L1 em todas as aulas e, as observações já realizadas em seu diário, tive a perspectiva de que teria uma evolução após a análise inicial, o que não ocorreu. Nesse sentido, ressalto que, assim como em outros dois, neste diário há evidências de entendimentos limitados do licenciando com relação ao seu processo formativo, que pode 


\section{Vol. 2, n. 3 - Edição Especial: Ciclos Formativos em Ensino de Ciências.}

ser em decorrência de dificuldades de reconhecimento na profissão ou, ainda, falta de leituras e participação nas aulas.

Os DBs caracterizados como reflexivos excludentes foram sete, que buscaram apresentar situações marcantes da aula. Nas escritas, os licenciandos ressaltam aspectos que lhes chamaram a atenção e que contribuem para a formação, porém os próprios licenciandos não apareceram incluídos na aula, há referência ao processo de formação dos colegas apenas, o que evidencia uma dificuldade de reconhecimento no grupo.

Identifiquei em L4 a categoria reflexiva excludente, para a licencianda:

"Hoje a aula foi interessante, a professora organizou grupos em que os colegas tiveram que discutir sobre a importância da epistemologia na formação de professores. Todos gostaram e se envolveram, as discussões foram muito significativas”. (DB, L4, 2018)

Na escrita da licencianda é possível identificar aspectos que evidenciam a reflexão, ou seja, aspectos marcantes da aula que podem contribuir ao processo de formação, como "interessante" e "muito significativas". Porém, a licencianda não aparece na escrita, ou seja, não está incluída no processo da aula.

Já na categoria reflexiva inclusiva foram caracterizados os outros sete DBs, em que os licenciandos evidenciam, por meio da escrita reflexiva, preocupação com a sua formação e com a formação dos demais colegas. Para Porlán e Martin (p. 25, 2000), "Se comienza a incorporar poco a poco um certo grado de diferenciación consciente entre lo que se describe espontaneamente y el análisis más sossegado, sistemático y racional”.

A perspectiva reflexiva inclusiva foi identificada em L9 ao relatar:

"A aula hoje foi muito interessante, pude perceber a importância dos aspectos epistemológicos na minha formação e de meus colegas. Como futura professora reconheço a importância dessas discussões na formação inicial porque assim, quando eu estiver na escola, terei um olhar mais ampliado acerca dos processos de ensinar $e$ aprender" (DB, L9, 2018). 


\section{Vol. 2, n. 3 - Edição Especial: Ciclos Formativos em Ensino de Ciências.}

A escrita de L9 demonstra um desenvolvimento significativo no processo reflexivo, pois a licencianda se reconhece como participante e, ainda, evidencia preocupação com a sua atuação docente. Tal característica acena para a importância do diário de bordo no processo formativo, pois os relatos realizados foram se tornando cada vez mais reflexivos e, com isso, potencializaram a formação docente.

\section{CONCLUSÃO}

O uso do diário de bordo no processo de formação inicial tem sido uma prática recorrente nos cursos de formação de professores que buscam qualificar o processo por meio da reflexão da prática. Nessa perspectiva, tenho utilizado o diário como um instrumento permanente nas aulas de práticas de ensino na licenciatura em Química. Nesse sentido, as escritas reflexivas realizadas nos diários de bordo de licenciandos em fase inicial de curso serviram de objeto de análise para o presente relato, que buscou identificar contribuições das discussões epistemológicas para o desenvolvimento da identidade docente dos futuros professores.

Ressalto que a transformação da prática docente implica em mudança de concepção da formação docente e dos saberes e conhecimentos que perpassam este fazer. Do ponto de vista metodológico, a forma de conceber a produção do conhecimento permite a evolução do processo, através das rupturas com saber pré-estabelecido. São estas rupturas do saber aprendido no cotidiano, que permitem uma discussão epistemológica do fazer docente, impedindo que as mesmas estejam dissociadas da prática docente, considerando que "o ato de ensinar não se destaca tão facilmente quanto se crê, da consciência de saber e que a melhor forma de aprender é ensinar (BACHELARD, 1997, p. 19)".

Nessa perspectiva, compreendendo as formas de constituição do conhecimento, defendo que se faz necessário uma dimensão crítica para permear a atividade profissional e, por conseguinte, a formação. Assim, destaco que trabalhar o CCR de Epistemologia e o Ensino de Ciências para licenciandos de $1^{\mathrm{a}}$ fase de curso foi um desafio que contribuiu 
Vol. 2, n. 3 - Edição Especial: Ciclos Formativos em Ensino de Ciências. para minha formação, em especial, pela possibilidade de compreender as distintas perspectivas reflexivas dos alunos no processo de constituição docente.

\section{REFERÊNCIAS}

BACHELARD, G. A Formação do Espírito Científico. Rio de Janeiro: Contraponto, 1996.

BARDIN, L. Análise de Conteúdo. 1. ed. São Paulo: Edições, 2011.

BRASIL. Ministério da Educação. Lei de Diretrizes e Bases da Educação Nacional no 9394/96. Brasília, Distrito Federal, 1996.

BRASIL. Ministério da Educação. Diretrizes Curriculares Nacionais Gerais para a Formação Inicial em nível superior e para a formação continuada. Resolução $n^{\circ} 2$ de

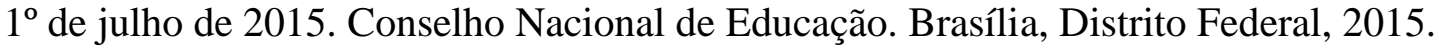

PORLÁN, R.; MARTÍN. R. EI diario del Profesor: Um recurso para la investigación em el aula. 8 ed. Sevilla: Díada Editora, 2000.

UFFS. Projeto Pedagógico do Curso de Química Licenciatura - Campus Cerro Largo/RS. Universidade Federal da Fronteira Sul, 2017.

ZEICHNER, K. M. A Formação Reflexiva de Professores: ideias e práticas. Educa, Lisboa, 1993. 